\title{
TU/e EmonOWEN

\section{Anteroposterior drawer measurements in the knee using an instrumented test device}

\section{Citation for published version (APA):}

Edixhoven, P., Huiskes, H. W. J., \& Graaf, de, R. (1989). Anteroposterior drawer measurements in the knee using an instrumented test device. Clinical Orthopaedics and Related Research, 247, 232-242.

\section{Document status and date:}

Published: 01/01/1989

\section{Document Version:}

Publisher's PDF, also known as Version of Record (includes final page, issue and volume numbers)

\section{Please check the document version of this publication:}

- A submitted manuscript is the version of the article upon submission and before peer-review. There can be important differences between the submitted version and the official published version of record. People interested in the research are advised to contact the author for the final version of the publication, or visit the $\mathrm{DOI}$ to the publisher's website.

- The final author version and the galley proof are versions of the publication after peer review.

- The final published version features the final layout of the paper including the volume, issue and page numbers.

Link to publication

\section{General rights}

Copyright and moral rights for the publications made accessible in the public portal are retained by the authors and/or other copyright owners and it is a condition of accessing publications that users recognise and abide by the legal requirements associated with these rights.

- Users may download and print one copy of any publication from the public portal for the purpose of private study or research.

- You may not further distribute the material or use it for any profit-making activity or commercial gain

- You may freely distribute the URL identifying the publication in the public portal.

If the publication is distributed under the terms of Article 25fa of the Dutch Copyright Act, indicated by the "Taverne" license above, please follow below link for the End User Agreement:

www.tue.nl/taverne

Take down policy

If you believe that this document breaches copyright please contact us at:

openaccess@tue.nl

providing details and we will investigate your claim. 


\title{
Anteroposterior Drawer Measurements in the Knee Using an Instrumented Test Device
}

\author{
P. Edixhoven, ${ }^{*}$ M.D., R. Huiskes, Ph.D., ANd R. DE GraAf, Ph.D.**
}

\begin{abstract}
A newly developed instrumented knee laxity tester was used to measure anteroposterior (AP) drawer parameters (Lachmann test) in populations of normal subjects and patients with anterior cruciate ligament (ACL) and posterior cruciate ligament (PCL) insufficiencies. The AP drawer tester features a differential electronic measuring procedure of displacements between patella and tuberosity over a continuous range between 180 and $-180 \mathrm{~N}$ of AP forces. In the statistical evaluation, shift and compliance (or stiffness) parameters at various forces are considered. In a representative normal population, all relevant parameters were established, thus creating a normal data base for future reference. The average normal $\mathbf{A P}$ drawer shift between maximal anterior and posterior forces $(180 \mathrm{~N})$ was $6.4 \pm 1.7 \mathrm{~mm}$. Right-left differences and male-female differences were found not to be statistically significant in any of the parameters. The validity of the instrumented drawer tester was confirmed relative to a group of patients with acute documented ligament insufficiencies. Measurements in two groups of patients with chronic postoperative knee instabilities revealed that although the diagnosis of instability could be confirmed, the results could hardly discriminate between ACL and PCL insufficiencies, probably due to unrecognized associated lesions at the time of operation and/or gradual postoperative developments of insufficiencies and deformities. An un-
\end{abstract}

\footnotetext{
* From the Department of Orthopaedics, Canisius Hospital, Nijmegen, The Netherlands.

** From the Department of Medical Statistics, University of Nijmegen, Nijmegen. The Netherlands.

Sponsored in part by the Nederlandse Sport Totalisator.

Reprint requests to Rik Huiskes, Ph.D., Biomechanics Section, Institute of Orthopaedics, University of Nijmegen, P.O. Box 9101, 6500 HB Nijmegen, The Netherlands.
}

Received: January 23, 1987. expected finding was that the mean laxities of the uninjured contralateral knees were significantly extended relative to the normal reference group, suggesting that these patients could have been classified as a high-risk group even before the time of injury.

The manual anteroposterior (AP) drawer test is widely applied in orthopedics to estimate the passive stability of the knee joint. The AP laxity of the knee upon AP loading of the tibia is primarily resisted by the cruciate ligaments. ${ }^{1.5}$ Hence, increased AP laxity is a measure for the extent of cruciate ligament lesions.

Although effective for diagnostic purposes and easily applicable in routine practice, the manual drawer test has the disadvantage of being subjective in nature. Hence, this test is less suitable to detect gradual changes in knee joint stability, to objectively evaluate effects of treatments, or to document laxity in large patient populations for clinical research. To overcome these disadvantages, several attempts were made to objectively measure the AP drawer. Measurement techniques were either based on roentgenographic analysis ${ }^{6.7,12,13}$ or on instrumented devices for direct external measurements. ${ }^{2.3 .9 .11}$

The latter technique is the subject of the present study. Using the differential displacement method whereby the AP shift of the tuberosity upon AP loading is quantified relative to the patella, representing the displacement of the distal femur, an instrumented 


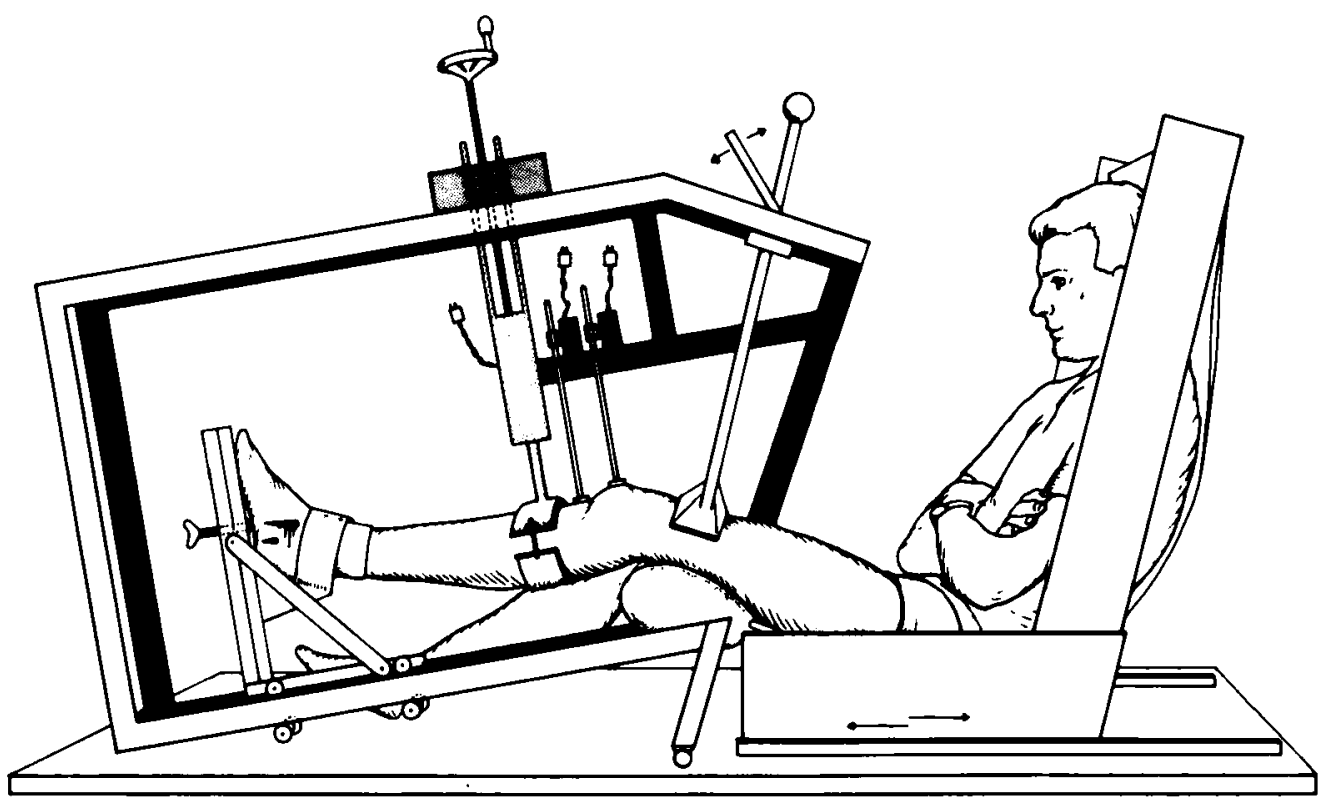

FIG. 1. Schematic drawing of the AP drawer tester.

drawer tester was developed. Electronic load and displacement-measuring sensors were connected to a microcomputer, enabling immediate representation of continuous AP laxity curves on a monitor and storage of multiple patient data for later analysis. The construction of this instrumented drawer tester and its accuracy and reproducibility in measuring the AP knee displacements and stiffness parameters were reported earlier. ${ }^{4}$

The purpose of the present study was (1) to create a data base for knee laxity parameters in normal persons; (2) to test the application of the laxity tester as a diagnostic tool in a patient group with documented cruciate lesions; and (3) to document the knee drawer parameters in groups of patients with chronic knee instabilities.

\section{MATERIALS AND METHODS}

The instrument developed for the present investigation is shown in Figure 1. Each leg is subsequently positioned in approximately $30^{\circ}$ of hip flexion, $25^{\circ}$ of knee flexion (Lachmann test), and neutral tibial rotation. The upper leg is secured with a thigh holder, and the foot is held in a foot holder. Displacement transducers are positioned on the tuberosity and on the patella. AP forces are administered manually with a spindle and measured with a load-cell. The displacement transducers and the load-cell are connected to a microcomputer, which evaluates the differential displacements (the drawer shift) and the forces online and displays a force-displacement curve on the monitor. This curve can be printed and added to the patient file. In addition, the values measured are stored on a floppy disc for later statistical analysis of patient populations. Further details were presented earlier. ${ }^{4}$

Before the results are analyzed, each force-displacement curve is corrected for the posteriorly directed gravity force on the lower leg, which is uniformly estimated at $30 \mathrm{~N} .{ }^{4}$ Figure 2 shows a schematic example of an AP drawer curve. The AP shift, as a function of the AP force, is strongly nonlinear, representing a relatively low resistance of the knee around zero force, increasing progressively to high resistances for high anterior and posterior forces. Due to energy dissipation within the collagenous structures, a hysteresis loop occurs, separating the loading curve from the unloading curve. Hence, an upper branch (representing the anterior-to-posterior shift) and a lower branch (representing the posterior-to-anterior shift) are obtained.

The following parameters of the AP drawer curve are calculated (Fig. 2): 


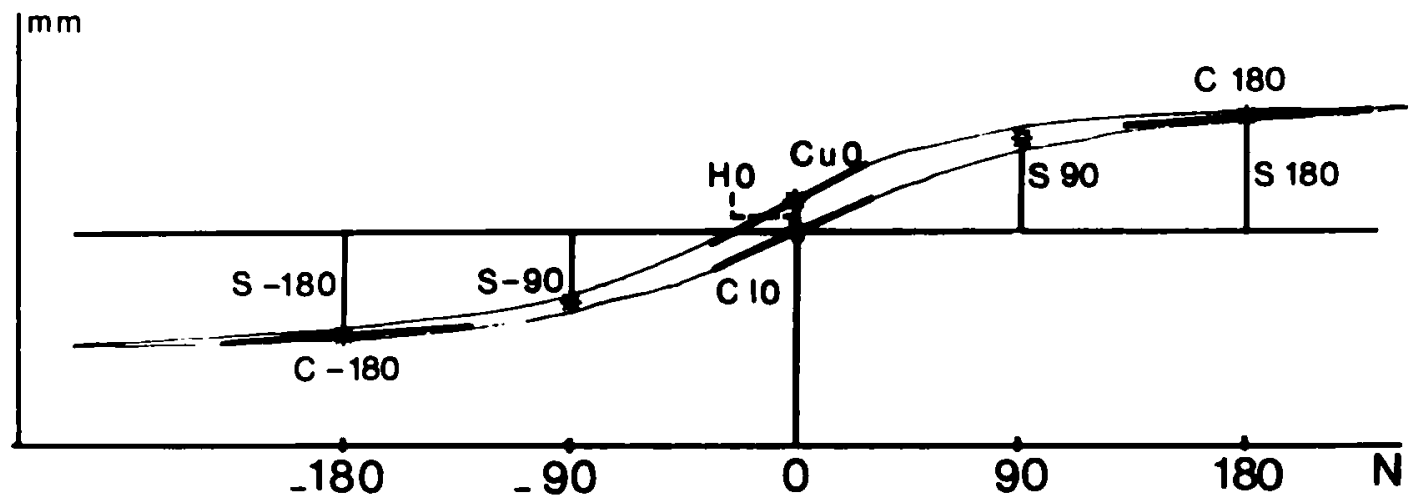

FIG. 2. Load (N)-displacement ( $\mathrm{mm}$ ) curves. The lower curve is posterior to anterior drawer, and the upper curve is anterior to posterior drawer. Parameters for compliance and laxity are computed with respect to the gravity-corrected force values of $0 \mathrm{~N}, 90 \mathrm{~N},-90 \mathrm{~N}, 180 \mathrm{~N}$, and $-180 \mathrm{~N}$.

\section{Shift Values}

$\mathrm{H}_{0}(\mathrm{~mm})$ : the "zero-force hysteresis," the distance between the lower and the upper branch at zero force.

$S_{-180}(\mathrm{~mm})$ : the average shift (lower and upper branch together) for a posterior force of $180 \mathrm{~N}$, relative to the lower branch position at zero force.

$\mathrm{S}_{-90}(\mathrm{~mm})$ : as $\mathrm{S}_{-180}$, but at a $90 \mathrm{~N}$ posterior force.

$\mathrm{S}_{90}(\mathrm{~mm})$ : as $\mathrm{S}_{-180}$, but at a $90 \mathrm{~N}$ anterior force.

$S_{180}(\mathrm{~mm})$ : as $S_{-180}$, but at a $180 \mathrm{~N}$ anterior force.

$\mathrm{T}_{90}(\mathrm{~mm})$ : the total shift between $90 \mathrm{~N}$ and -90 $\mathrm{N}$ forces.

$T_{180}(\mathrm{~mm})$ : the total shift between $180 \mathrm{~N}$ and $-180 \mathrm{~N}$ forces.

\section{Compliance Values}

$\mathrm{C}_{\mathrm{uo}}(\mathrm{mm} / \mathrm{N})$ : the compliance (slope) of the upper branch at zero force.

$\mathrm{C}_{10}(\mathrm{~mm} / \mathrm{N})$ : the compliance (slope) of the lower branch at zero force.

$\mathrm{C}_{-180}(\mathrm{~mm} / \mathrm{N})$ : the average compliance (lower and upper branch taken together) at a posterior force of $180 \mathrm{~N}$.

$\mathrm{C}_{180}(\mathrm{~mm} / \mathrm{N})$ : as $\mathrm{C}_{-180}$, but at an anterior force of $180 \mathrm{~N}$.

The calculated values are always based on two complete measurement cycles of the AP drawer. The values are obtained from linearization of the curve segments with respect to certain intervals around the force values concerned (Fig. 2) by using distribution-free estimation methods. ${ }^{4}$ The compliance $(\mathrm{mm} / \mathrm{N})$ is the inverse of the stiffness $(\mathrm{N} / \mathrm{mm}) . \mathrm{C}_{180}$ and $\mathrm{C}_{-180}$ can be considered as esti- mates of the end-point compliance, the inverse of the end-point stiffness.

Two additional parameters calculated are the tuberosity depths relative to the patella, first, at the starting position (lower branch) of zero force $\left(\mathrm{P}_{0}, \mathrm{~mm}\right)$ and, second, averaged over the upper and the lower branches at a $90 \mathrm{~N}$ posterior force $\left(P_{-90}, \mathrm{~mm}\right)$. The value $P_{0}$ has an anatomic significance, useful for describing right-left differences. If it is assumed that the tuberosity depth must anatomically be equal on both sides, then a rightleft comparison of the calculated $P_{0}$ values gives an indication of the reproducibility of the setting and positioning procedure that determines the (neutral) reference position of the tibia relative to the femur in the instrumented drawer test. The value of $P_{-90}$ is related to the clinical gravity test (Sag test ${ }^{2}$ ), giving an indication of the resistance of the posterior cruciate without consideration of the neutral position, which is not always accurately determined. ${ }^{4}$ Only the differences of $P_{0}$ and $P_{-90}$ between right and left knees are considered here.

To assess the mean values and standard deviations of the AP drawer parameters in a normal population, a series of 34 normal subjects (Group 1) was investigated. Their ages varied from 15 to 26 years; 14 were females and 20 were males. None of these had a history of knee complaints or trauma. In each case the aforementioned parameters were calculated from the AP drawer test results, and paired Student's $t$-tests were performed to study right-left differences.

To test the applicability of the drawer tester as a diagnostic tool, eight patients (Group 2) were investigated. These patients, aged 16-30 years, one woman and seven men, presented at the emergency clinic with hemarthrosis of one knee after a 
sports trauma. None of these patients had a history of knee complaints; the contralateral knee was considered normal after anamnesis and manual examination. All these patients could be analyzed in the drawer tester without anesthesia. Afterwards, all were inspected with the arthroscope.

Finally, the knee drawer parameters were determined in patients with chronic complaints of instability of one knee (Group 3) after complete rupturing and subsequent operative repair or reconstruction of either the anterior cruciate ligament (ACL) or the posterior cruciate ligament (PCL). The ACL group (Group 3A) consisted of 29 patients, aged $23-50$ years, including six females and 23 males. During the operation the PCLs of these patients were found to be normal. The PCL Group (Group 3B) consisted of 28 patients, aged 17-53 years, including 11 females and 17 males. During the operation the ACLs were considered normal. The contralateral knees of the patients in these two subgroups had no history of complaints and were considered normal after manual inspection. The instrumented drawer test took place one to 12 years after the operation, and no such test had been carried out preoperatively. Hence, the findings were evaluated relative to the documented perioperative information and were compared with a reference group of 64 normal subjects (Group 3C), varying in age from 15 to 60 years, including 12 females and 52 males with no history of knee complaints or trauma. This reference group is a different one from the normal Group 1 because a slightly different definition of the AP drawer parameters was used in an earlier stage of the project when Group 3 was evaluated.

\section{RESULTS}

\section{Normal Data Base (Group 1)}

The means and standard deviations of the knee drawer parameters for the whole group are shown in Table 1. The shift and the compliance parameters vary considerably within the group. The total AP laxity between $180 \mathrm{~N}$ and $-180 \mathrm{~N}\left(\mathrm{~T}_{180}\right)$, for instance, has a mean value of $6.4 \mathrm{~mm}$ with an $\mathrm{SD}$ of $1.7 \mathrm{~mm}$. Hence, assuming a normal distribution for this parameter, about $95 \%$ of the population has a $T_{180}$ value (average of both knees) between 3.0 and $9.8 \mathrm{~mm}$. The right-left difference of this parameter would vary for about $95 \%$ of the population between -2.1 and 1.5 $\mathrm{mm}$. The right-left differences in tuberosity depths have a mean of -0.6 in the unloaded
TABLE 1. The Knee Drawer Parameters for the Normal Subjects (Group 1, $n=34$ )

\begin{tabular}{|c|c|c|c|c|c|c|}
\hline Parameter & \multicolumn{3}{|c|}{$(R+L) / 2$} & \multicolumn{3}{|c|}{$R-L$} \\
\hline \multicolumn{7}{|c|}{$\begin{array}{l}\text { Tuberosity depth } \\
\qquad(\mathrm{mm})\end{array}$} \\
\hline$P_{0}$ & \multicolumn{3}{|c|}{ - } & \multicolumn{2}{|c|}{$-0.6 \pm$} & 2.2 \\
\hline$P_{-90}$ & \multicolumn{3}{|c|}{ 一 } & \multicolumn{2}{|c|}{$-0.5 \pm$} & 2.0 \\
\hline \multicolumn{7}{|c|}{ Hysteresis (mm) } \\
\hline $\mathrm{H}_{0}$ & \multicolumn{2}{|c|}{$0.5 \pm$} & 0.4 & \multicolumn{2}{|c|}{$-0.1 \pm$} & 0.4 \\
\hline \multicolumn{7}{|c|}{ Total shift (mm) } \\
\hline $\mathrm{T}_{90}$ & \multicolumn{2}{|c|}{$4.9 \pm$} & 1.4 & \multicolumn{2}{|c|}{$-0.2 \pm$} & 0.7 \\
\hline$T_{180}$ & \multicolumn{2}{|c|}{$6.4 \pm$} & 1.7 & \multicolumn{2}{|c|}{$-0.3 \pm$} & 0.9 \\
\hline \multicolumn{7}{|l|}{ Shift (mm) } \\
\hline $\mathbf{S}_{-180}$ & \multicolumn{2}{|c|}{$-3.0 \pm$} & 0.9 & \multicolumn{2}{|c|}{$0.1 \pm$} & 0.6 \\
\hline $\mathbf{S}_{-90}$ & \multicolumn{2}{|c|}{$-2.4 \pm$} & 0.7 & \multicolumn{2}{|c|}{$0.1 \pm$} & 0.6 \\
\hline $\mathbf{S}_{90}$ & \multicolumn{2}{|c|}{$2.6 \pm$} & 1.1 & \multicolumn{2}{|c|}{$-0.1 \pm$} & 0.7 \\
\hline $\mathbf{S}_{180}$ & \multicolumn{3}{|c|}{$3.4 \pm$} & \multicolumn{2}{|c|}{$-0.1 \pm$} & 0.8 \\
\hline \multicolumn{7}{|c|}{$\begin{array}{l}\text { Compliance } \\
\qquad\left(10^{-4} \mathrm{~mm} / \mathrm{N}\right)\end{array}$} \\
\hline$C_{-180}$ & 59 & \pm & 24 & -5 & \pm & 38 \\
\hline $\mathrm{C}_{\mathrm{uo}}$ & 471 & \pm & 31 & -14 & \pm & 142 \\
\hline$c_{10}$ & 453 & & 18 & -13 & & 48 \\
\hline$C_{180}$ & 71 & \pm & 22 & 2 & \pm & 30 \\
\hline
\end{tabular}

Values are means \pm SD

(gravity-corrected) case and -0.5 with a $90 \mathrm{~N}$ posterior force. Larger absulute mean values for nearly all parameters were found in the left knees. However, these differences were not significant $(p>0.05)$.

Statistical analysis of the male-female differences revealed no significant effects in the parameters, according to two-sample tests of Student $(p>0.05)$. However, the absolute means of all parameters, with the exception of the zero force compliances and the tuberosity depths at $-90 \mathrm{~N}$, were larger in females, often $10 \%$ or more.

The results for this normal group are summarized in Figure 3, showing the mean $( \pm \mathrm{SD})$ drawer curve of the group as a shaded area (gravity-corrected). Also shown are the (gravity-corrected) findings reported by Markolf et al.,9,10 Shino et al.," and Daniel et al. ${ }^{3}$

\section{Acute Patients (Group 2)}

The results of the acute patient Group 2 are presented in Table 2 . The patients were 


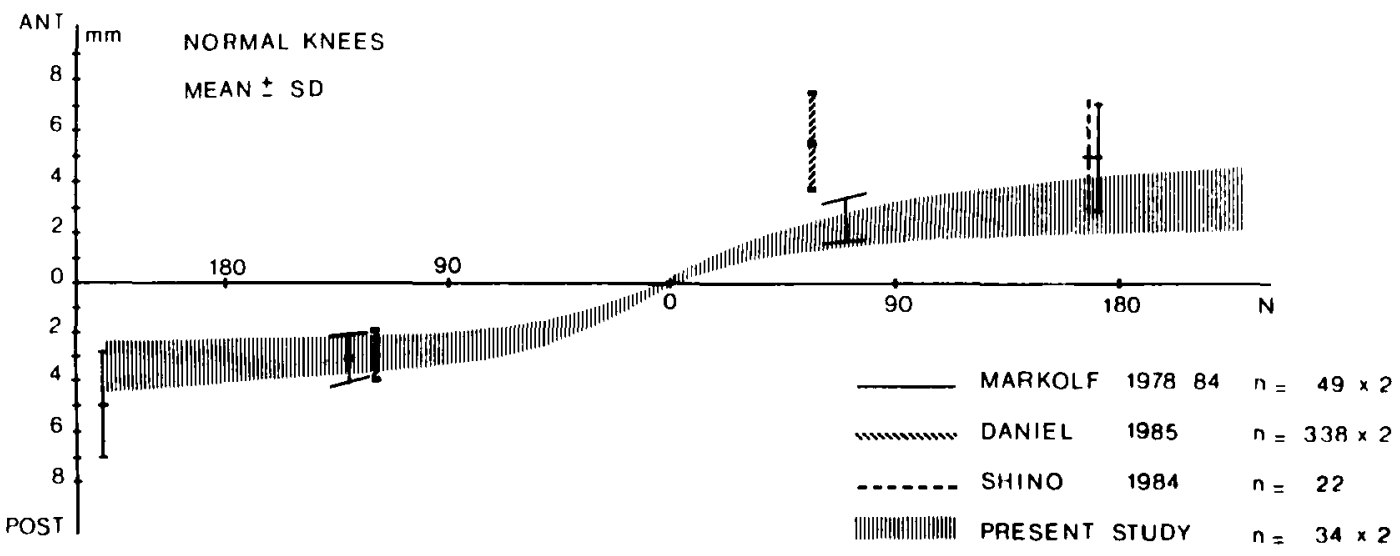

FIG. 3. A comparison of mean \pm SD shifts corrected for gravity in normal subjects obtained in studies by Markolf et al..$^{910}$ and Daniel et al., ${ }^{3}$ noninjured knees by Shino et al.," and the normal group of the present study.

divided into three diagnostic subcategories. Diagnosis Group N (no cruciate lesions) consisted of Patients 1, 2, and 3. In each of these patients, no lesions of the cruciates were revealed during arthroscopy. Manual stability inspection under anesthesia did not reveal abnormal laxities. The hemarthrosis was found to be caused by a patellofemoral osteochondral defect. In diagnosis Group A (anterior cruciate lesion), consisting of $\mathbf{P a}$ tients 4 through 7, (sub)total ruptures of the anterior cruciate were diagnosed by arthros-

TABLE 2. Differences Between the Intact Knee and the Hemarthrotic Knee in Eight Patients (Group 2D) After Acute Knee Injury

\begin{tabular}{|c|c|c|c|c|c|c|c|c|}
\hline \multirow[b]{2}{*}{ Parameter } & \multicolumn{3}{|c|}{$\begin{array}{l}\text { Diagnosis N } \\
\text { Patient No. }\end{array}$} & \multicolumn{4}{|c|}{$\begin{array}{l}\text { Diagnosis A } \\
\text { Patient No. }\end{array}$} & \multirow{2}{*}{$\begin{array}{c}\text { Diagnosis } L \\
\text { Patient No. } \\
8\end{array}$} \\
\hline & 1 & 2 & 3 & 4 & 5 & 6 & 7 & \\
\hline \multicolumn{9}{|c|}{ Tuberosity depth (mm) } \\
\hline$P_{0}$ & -0.3 & 0.4 & -6.7 & 2.1 & 0.2 & -0.8 & 2.3 & 1.4 \\
\hline$P_{-90}$ & -1.5 & -0.6 & -6.4 & 3.1 & 1.1 & 0.9 & 2.7 & 2.3 \\
\hline \multicolumn{9}{|l|}{ Hysteresis (mm) } \\
\hline $\mathrm{H}_{0}$ & -0.4 & -0.3 & -0.3 & -0.6 & -1.9 & -1.3 & -0.3 & -0.8 \\
\hline \multicolumn{9}{|l|}{ Total shift $(\mathrm{mm})$} \\
\hline $\mathrm{T}_{90}$ & 1.2 & 0.1 & -0.3 & -4.7 & -3.1 & -5.4 & -2.9 & -2.1 \\
\hline $\mathrm{T}_{180}$ & 0.3 & -0.4 & -0.6 & -7.3 & -5.1 & -8.1 & -5.3 & -3.0 \\
\hline \multicolumn{9}{|l|}{ Shift (mm) } \\
\hline$S_{-180}$ & -1.5 & 0.4 & 1.4 & 0.8 & 1.0 & 3.2 & 0.3 & 1.8 \\
\hline$S_{-90}$ & -1.2 & -0.2 & 0.3 & 1.0 & 0.8 & 1.8 & 0.4 & 0.9 \\
\hline$S_{90}$ & 0.0 & -0.1 & 0.6 & -3.6 & -2.2 & -3.6 & -2.4 & -1.2 \\
\hline $\mathrm{S}_{180}$ & -1.1 & -0.1 & 0.8 & -6.4 & -4.1 & -5.0 & -4.9 & -1.1 \\
\hline \multicolumn{9}{|l|}{$\begin{array}{l}\text { Compliance } \\
\qquad\left(10^{-4} \mathrm{~mm} / \mathrm{N}\right)\end{array}$} \\
\hline $\mathrm{C}_{-180}$ & 12 & -3 & -63 & 0 & 23 & -112 & -9 & -129 \\
\hline $\mathrm{C}_{\mathrm{uo}}$ & -115 & 288 & 274 & -366 & -336 & -239 & -130 & -149 \\
\hline $\mathrm{C}_{\mathrm{lo}}$ & 131 & -99 & 343 & -184 & -361 & -180 & -236 & -154 \\
\hline$C_{180}$ & -92 & -21 & 35 & -240 & -145 & -192 & -185 & -43 \\
\hline
\end{tabular}


copy and manual examination under anesthesia. The last diagnosis Group $U$ (uncertain) contains only Patient 8 . In this case, no cause for the hemarthrosis was detected at arthroscopy, while manual examination under anesthesia did not reveal abnormal instability.

Comparing the differences between the intact and the hemarthrosis knees in the AP drawer parameters of Group N (Patients 1, 2 and 3, Table 2) with the right-left differences in the normal group (Table 1) revealed that generally the values for the patients were well within the normal range (mean \pm 2 SD). Patients 4 through 7 clearly show higher than normal laxities and compliances in the hemarthrosis knee. It is also evident that the increased laxity predominantly concerns the anterior direction. Both the differences in posterior shifts and the posterior compliances of Patient 6 suggest that in this case additional trauma exists in the PCL.

It is obvious from these results that the diagnoses in Groups $\mathrm{A}$ and $\mathrm{N}$ are supported by the results of the instrumented AP drawer test. The values for Patient 8 , whose diagnosis was uncertain, do not reveal a clear pattern. The total shift values $\left(T_{90}\right.$ and $\left.T_{180}\right)$ in the hemarthrotic knee are somewhat increased relative to the unaffected knee and suggest a mild PCL lesion.

\section{Chronic Patients (Group 3)}

All knee drawer parameters in Group 3 were evaluated in terms of intact-injured differences, relative to the findings for Group $3 \mathrm{C}$. The average right-left differences in the latter group were similar to those in the normal Group 1.

Considering the intact-injured differences in the AP drawer parameters of the ACL Group 3A, all the mean shift and compliance parameters of the injured knees increased relative to the noninjured knees. It is notable in this ACL group that although the anterior shifts $\left(S_{90}, S_{180}\right)$ have on the average increased much more, there is still a statisti- cally significant increase of the posterior shifts $\left(\mathrm{P}_{-90}, \mathrm{~S}_{-180}, \mathrm{~S}_{-90}\right)$. On the average, the $S D$ values in the $A C L$ group are larger than those in the normal reference group, indicating that the variation is higher, in other words, the ACL group is less uniform than the reference group.

The intact-injured differences in the AP drawer parameters of the PCL Group 3B show similar effects. Again, all the mean shift and compliance parameters of the injured knees are increased relative to the noninjured knees. The mean increases in hysteresis $\left(\mathrm{H}_{0}\right)$ and total shifts $\left(\mathrm{T}_{90}\right.$ and $\left.\mathrm{T}_{180}\right)$ are similar to those in the ACL group. However, the mean increases in posterior shifts $\left(S_{-180}\right.$, $S_{-90}$ ) are of the same magnitude as the mean increases in anterior shifts $\left(S_{180}, S_{90}\right)$, which is remarkable for this PCL group. As in the ACL group, the standard deviations are higher than in the reference group, again indicating that the group is nonuniform.

The results are graphically represented in Figure 4, which shows the mean \pm SD shifts as shaded areas and compares the injured knees of the ACL group (Fig. 4A) and the PCL group (Fig. 4B) relative to the combined right and left knees of the reference group. These figures illustrate clearly that in both the chronic patient groups, the anterior as well as the posterior laxities are higher than normal.

It was found in the PCL group (and not in the ACL group) that the mean zero-force tuberosity depth $P_{0}$ differs significantly (mean, $3.5 \mathrm{~mm}$ ) from the noninjured knees. Hence, the neutral reference position of the tibia, relative to the femur (patella), at the beginning of the AP drawer test (gravity-corrected) is on the average $3.5 \mathrm{~mm}$ more posterior in the injured knee than in the noninjured knee. If the average AP drawer curve of the PCL group in Figure 4B was corrected with $3.5 \mathrm{~mm}$, based on the anatomic hypothesis that at zero force the position of the tibia relative to the femur must be equal on both sides, it was found that the mean anterior shifts $\left(\mathbf{S}_{180}\right)$ in the injured and the noninjured 

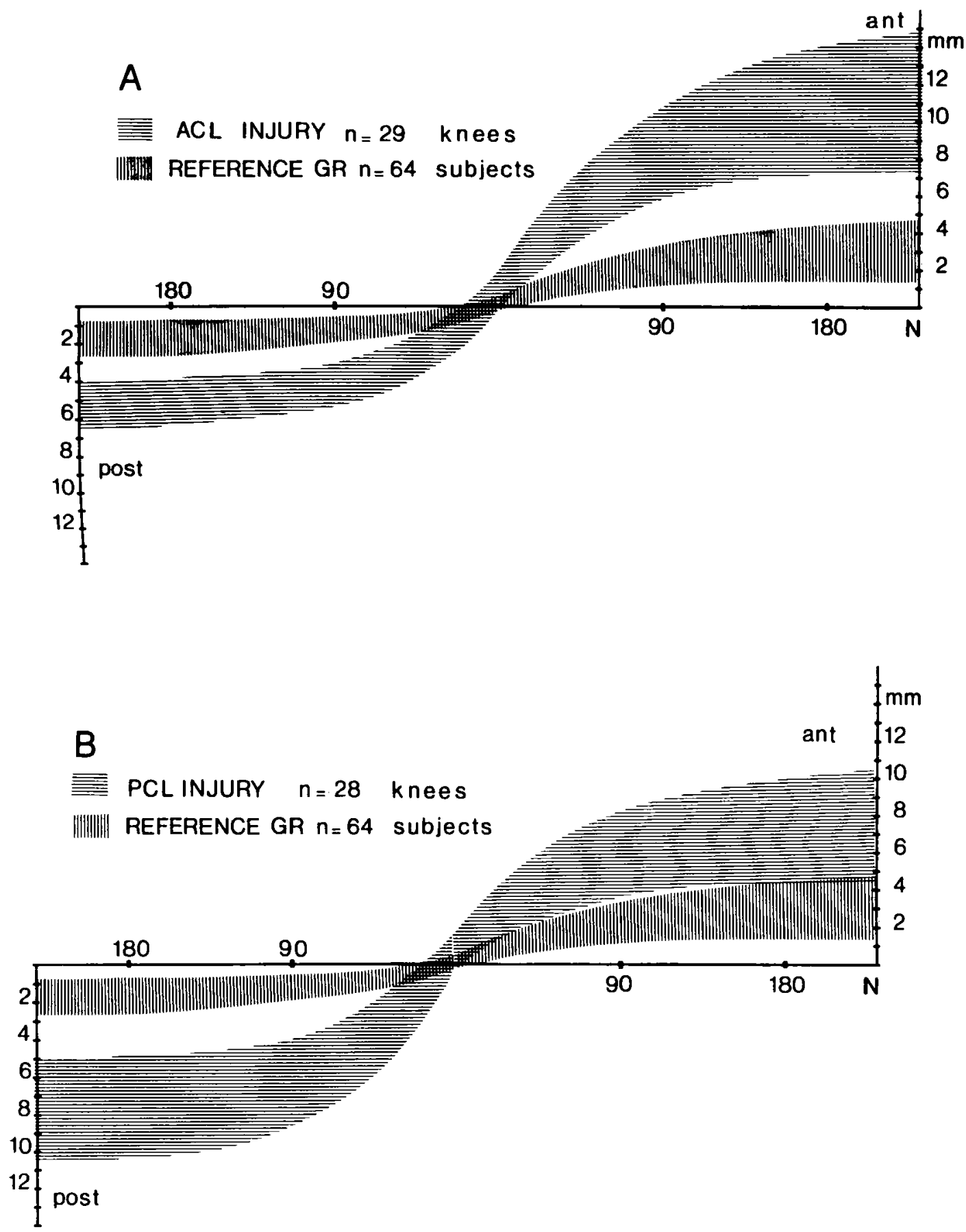

FIGS. 4A AND 4B. A comparison of the mean \pm SD shifts of (A) the ACL- and (B) the PCL-injured knee groups relative to the right and left knees of the reference group. 


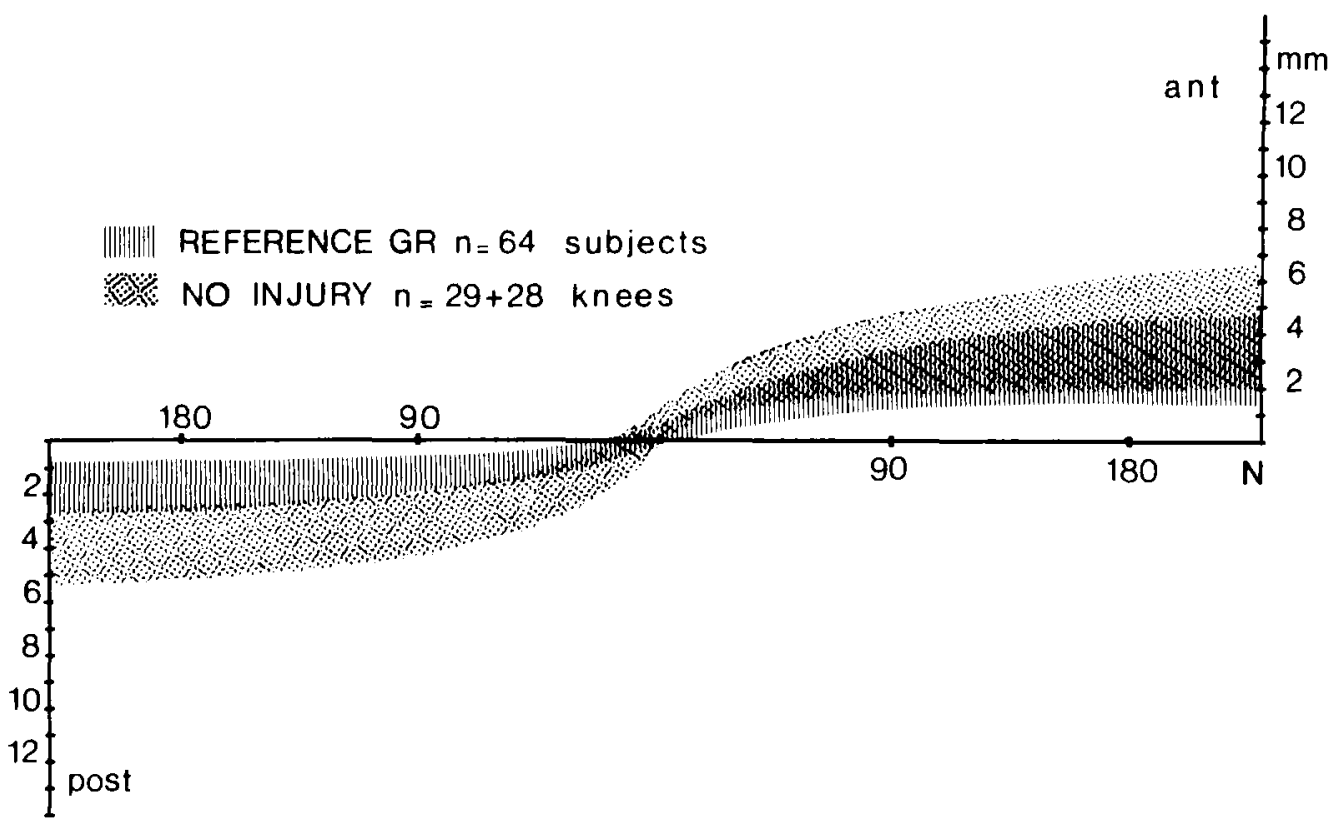

FIG. 5. A comparison of the mean \pm SD shifts of the noninjured knees of the ACL and PCL groups relative to the combined right and left knees of the reference group.

knees are almost equal (injured: $3.5 \mathrm{~mm}$; noninjured: $4.1 \mathrm{~mm}$ ), suggesting that, on the average, the anterior cruciates in this group would indeed be intact.

A remarkable phenomenon is seen when considering the values of the AP drawer parameters of the noninjured knees of the $\mathrm{ACL}$ and PCL groups. The absolute values of all mean shift and compliance parameters of these noninjured, contralateral knees were considerably higher than those in the reference group. This is illustrated in Figure 5, in which the areas of mean \pm SD shifts of the noninjured knees of the ACL and PCL groups are compared with the right and left knees of the reference group. Evidently, the noninjured knees in these groups cannot be considered normal.

Assuming the right-left, respectively, intact-injured differences of the parameters in the reference, ACL, and PCL groups to be distributed normally, the estimated probability distributions of the anterior shift $\mathbf{S}_{180}$ and the posterior shift $\mathbf{S}_{-180}$ are shown in Figure
6. It follows from these graphs that the probability distributions of the chronic $A C L$ and PCL groups differ from those of the reference group. However, it is also evident that the $\mathrm{ACL}$ and PCL groups cannot be discriminated easily from each other. The widths of the distributions of the patient groups indicate their nonuniformity. Evidently (Fig. 6B), the ACL group displays a more uniform behavior in the posterior drawer test, suggesting that isolated ACL lesions are more common than isolated PCL lesions.

\section{DISCUSSION}

The AP drawer parameters evaluated in Group 1 give an extensive inventory of gravity-corrected AP laxity characteristics in a normal population. As reported earlier, ${ }^{4}$ the accuracy of the measuring procedure was better than $10 \%$, based on tests with knee joint specimens. The variation of the shift values in this normal population (SD values) is about three to five times larger than the 

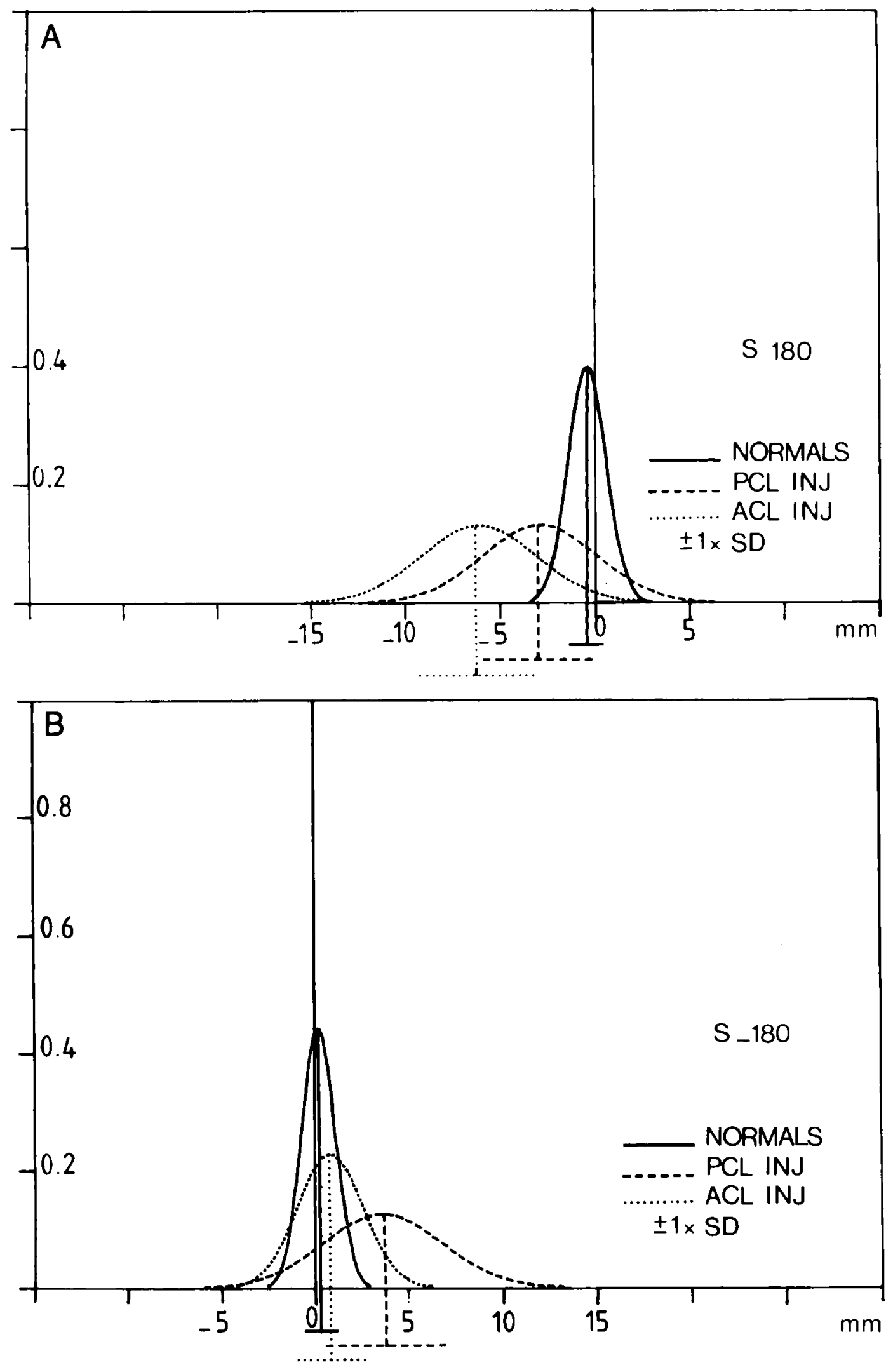
FIGS. 6A AND 6B. The estimated probability distributions for the right-left differences (reference group) and intact-injured differences (ACL and $\mathrm{PCL}$ insufficiency groups) with respect to (A) the anterior shift at $180 \mathrm{~N}$ and (B) the posterior shift at $-180 \mathrm{~N}$.

variability (reproducibility) in repeated measurements of individual knees. ${ }^{4}$ Some of the parameter values can be compared with results reported for normal subjects in the literature (Fig. 3). Comparing the present results with those of Markolf et al. ${ }^{9.10}$ however, at higher forces, the shift values of the results of those authors tended to be higher. This may be an effect of femoral motions within the fixation, which were not corrected by a differential measurement procedure in the test device of Markolf et al. ${ }^{9,10}$ The differential method applied by Shino et al. " is comparable with the one used here. Those authors reported measurements on the noninjured knees of 22 patients with unilateral ACL insufficiencies and reported only the anterior shift at $200 \mathrm{~N}$ and the stiffness (inverse of the compliance) at $50 \mathrm{~N}$ anterior forces. Both their mean shift values and standard deviations are higher than found here. This may be due to the fact that the noninjured knees of a patient group, which Shino et al. ${ }^{\prime \prime}$ measured, may not be considered a normal population, as suggested by the present findings. Daniel et al. ${ }^{3}$ also applied a differential (tuberosity relative to patella) measuring method in a simple device, whereby the leg is not fixed in a frame. Those authors reported mean anterior and posterior shifts at $89 \mathrm{~N}$ in a normal population of 338 subjects. Whereas their posterior shifts are similar to the ones in the present study, their anterior shifts are considerably higher, the cause for which is uncertain.

Although no significant right-left differences were found for any of the mean parameters in the normal group as a whole, the left knee had, on the average, the highest laxity.

Assuming a normal distribution for the parameters in the population, the present results suggest that in about $95 \%$ of the subjects, the absolute right-left differences in total AP shifts $\left(T_{180}\right)$ are less than $2.1 \mathrm{~mm}$ (which is about $30 \%$ of the normal mean) and the absolute differences in tuberosity depth at zero force $\left(\mathrm{P}_{0}\right)$ are less than $5.0 \mathrm{~mm}$. The studies of Markolf et al. ${ }^{9,10}$ suggested that the absolute right-left differences in total AP shifts at $200 \mathrm{~N}$ (without gravity correction) in $95 \%$ of normal subjects $(n=49)$ will vary up to $5.2 \mathrm{~mm}$, which is more than twice that found in the present study.

The validity of the AP drawer tester as a diagnostic tool was studied with acute patients. Although the number of patients was small and no PCL injury occurred in the group, the correlation between results from arthroscopic inspection and manual examination under anesthesia and the AP drawer values was excellent. A comparison of the values of the total shifts $T_{90}$ and $T_{180}$ (Table 2) relative to those in the normal group (Table 1) obviously leads to the conclusion that Patients 4-7 suffer from cruciate insufficiencies, Patients 1-3 do not, and that there is reason for doubt relative to Patient 8 . Examination of the anterior and posterior shift and compliance values clearly indicates that Patients 4-7 have anterior cruciate lesions. In addition to the clinical diagnosis, the parameter values suggest that Patient 6 has some concomitant PCL damage. PCL damage is also suggested in Patient 8 . The values for the differences between hysteresis $\left(\mathrm{H}_{0}\right)$ and tuberosity depths $\left(\mathrm{P}_{0}\right.$ and $\left.\mathrm{P}_{-90}\right)$ are not consistent.

The measurement results of the patients with chronic instability of one knee were less suitable for comparative purposes because preoperative evaluations were not made, and the state of the ligaments at the time of measurements were unknown. However, some interesting findings justify their discussion in the context of the present paper. In both the ACL and the PCL groups, significant increases in virtually all mean knee drawer parameters (shifts and compliances) were 
found relative to normal, which confirmed the clinical diagnoses of knee instability in the groups as a whole. However, although the mean values in the $A C L$ group pointed at anterior instabilities and those in the PCL group at posterior instabilities, the differences between anterior and posterior parameters were not significant in each case, although at the time of the operation a clear distinction was established. There are three possible explanations for this discrepancy. First, it is feasible that the ligament lesions found perioperatively were not purely ACL or PCL. Even when the ligaments are visually inspected, the extent of ligament injury cannot always be clearly revealed. ${ }^{8}$ Second, it is not impossible that PCL insuffciency developed gradually postoperatively in the ACL patients, and ACL insufficiency in the PCL patients, due to the general instability of the knees. A third possibility is related to the difficulty of determining the zero-shift reference position in the unstable knee. In particular, when the PCL is injured, the tibia tends to sag posteriorly under the influence of gravity. Although the results are gravity-corrected, this correction is not exact but based on average anthropometric data. In the mean tuberosity depth at zero force $\left(\mathrm{P}_{0}\right)$ of the PCL group, a significant increase was found of $3.5 \mathrm{~mm}$ relative to the contralateral knee, pointing in this direction. If the posterior shift values of the PCL group were corrected with this amount, a significant reduction in the anterior shifts would result, hence a significant difference with the $\mathrm{ACL}$ group.

Unexpected findings in the ACL and PCL groups were the higher than normal average laxities in the unaffected contralateral knees. This may imply that the patients concerned belong to a high-risk population, having increased bilateral knee laxities even before the time of unilateral injury.

The instrumented test developed for this study, based on a differential measurement in a semiconstrained fashion, uses the application of large forces and produces many useful parameters in acute and chronic pa- tients. This information can be highly relevant in clinical evaluations of large patient groups and can be used to study effects of certain treatment methods. It is also useful to document joint laxity in the patient files for the purpose of comparing preoperative with postoperative changes. In the case of individual diagnoses, however, the limitations of the method must be recognized, and a final decision must be based on a thorough clinical examination in addition.

\section{REFERENCES}

1. Butler, D. L., Noyes, F. R., and Grood, E. S.: Ligamentous restraints to AP drawer in the human knee. A biomechanical study. J. Bone Joint Surg. 62A:259, 1980.

2. Dandy, D. J., and Pusey, B. J.: The long term results of unrepaired tears of the posterior cruciate ligament. J. Bone Joint Surg. 64B:92, 1982.

3. Daniel, D., Malcolm, L. L., Losse, G., Stone, M. L., Sachs, R., and Burks, R.: Instrumented measurements of anterior laxity of the knee. J. Bone Joint Surg. 67A:720, 1985.

4. Edixhoven, P., Huiskes, R., de Graaf, R., van Rens, T. J. G., and Slooff, T. J.: Accuracy and reproducibility of an instrumented knee-drawer tester. J. Orthop. Res. 5:378, 1987.

5. Fukubayashi, T., Torzilli, P. A., Sherman, M. F., and Warren, R. F.: An in vitro biomechanical evaluation of anterior-posterior motion of the knee. Tibial displacement, rotation and torque. J. Bone Joint Surg. 64A:258, 1982.

6. Jacobson, K.: Gonylaxometry. Acta Orthop. Scand. 52 [Suppl. 194]:1, 1981.

7. Kennedy, J. D., and Fowler, P. J.: Medial and anterior instability of the knee. J. Bone Joint Surg. 53A:1257, 1971.

8. Kennedy, J. D., Hawkins, R. J., Willis, R. B., and Danylchuck, K. D.: Tension studies of human knee ligaments. J. Bone Joint Surg. 58A:350, 1976.

9. Markolf, K. L., Graff-Radford, A., and Amstutz, H. C.: In vivo knee stability. A quantitative assessment using an instrumented testing apparatus. J. Bone Joint Surg. 60A:664, 1978.

10. Markolf, K. L., Kochan, A., and Amstutz, H. C.: Measurement of knee stiffness and laxity in patients with documented absence of the anterior cruciate ligament. J. Bone Joint Surg. 66A:242, 1984.

11. Shino, K., Ohta, N., Horibe, S., and Ono, K.: Invivo measurement of $A P$ instability in the $A C L$ disrupted knees and in the post-operative knees. Orthop. Trans. 9:394, 1984.

12. Staubli, H. U., Noesberger, B., and Jakob, R. P.: The drawer sign of the knee in extension, a prospective study. Orthop. Trans. 7:585, 1983.

13. Torzilli, P. A., Greenberg, R. L., and Insall, J.: An in vivo biomechanical evaluation of anterior posterior motion of the knee. Roentgenographic measurement technique, stress machine and stable population. J. Bone Joint Surg. 63A:960, 1981 